Research Article

\title{
Dynamic Behavior of Soft Subgrade Soils Treated with Boron Waste
}

\author{
Volkan Okur (D) and Kubra Akinci \\ Eskisehir Osmangazi University, Department of Civil Engineering, Eskişehir, Turkey \\ Correspondence should be addressed to Volkan Okur; vokur@ogu.edu.tr
}

Received 11 July 2018; Accepted 8 October 2018; Published 23 October 2018

Academic Editor: Antonio Gloria

Copyright (C) 2018 Volkan Okur and Kubra Akinci. This is an open access article distributed under the Creative Commons Attribution License, which permits unrestricted use, distribution, and reproduction in any medium, provided the original work is properly cited.

\begin{abstract}
A series of laboratory tests using resonant column and dynamic torsional shear tests were conducted on kaolinite and montmorillonite clays treated with boron waste. The effect of the boron waste on the dynamic characteristics of two clays was studied considering the effects of the plasticity index. Pulverized boron waste was mixed with the clay soils in different proportions. It has been seen that treatment with boron waste improved the dynamic properties of the two clays. However, increasing the amount of boron waste does not affect the dynamic characteristics of the samples in the same proportions. Increasing the amount of boron waste in the mixture increased the initial shear modulus of the montmorillonite clay up to $300 \%$ compared to untreated samples, whereas the reaction of the kaolinite clay with boron waste treatment was moderate. Degradation curves of treated and untreated soils in regard to shear strain are presented. In general treatment, success is dependent on the amount of boron waste and the clay type. The continuous increase with the amount of boron waste in the shear modulus and damping ratio is apparent on both clays.
\end{abstract}

\section{Introduction}

The dynamic response of railways or road pavements is affected from the combination of its three subelements: the vehicles, course/track bedding, and subgrade soil. The road or railway traffic is a dynamic loading environment that imposes various repetitive loads on the superstructure. Vehicles moving with different speeds generate waves, which propagate through the superstructure to the subgrade soil affecting the serviceability level. Even though the period of the loading is on the order of $0.1 \mathrm{~s}$ to a few seconds, the number of repetitions is large. In addition, adding the low strength, large deformation or high swelling characteristics of soft subgrade soils to the equation usually results as a deterioration of the superstructure. Preventive measures or remedial actions are needed for these kinds of unstable subgrade soils, which can affect the long-term performance and stability. There are different approaches to the problem such as soil replacement (replacing the soft soil with a highgrade granular material) or soil improvement (mechanical or chemical stabilization) $[1,2]$. The most preferred method is soil stabilization as the soil replacement is a costly operation.

Since there are various stabilization techniques, chemical stabilization is the most used method in treatment of clay soils. Chemical stabilizers such as lime, cement, and fly ash are widely used in practice for improving the geotechnical properties of soils. These stabilizing agents are generally preferred because of their cementitious components. These constituents modify and stabilize soft soil through various reactions such as cation exchange, flocculation, and agglomeration [3-6]. Due to the low cost of application, use of appropriate waste materials has the double benefit of chemical stabilization of soils along with utilization of the waste.

Boron is a chemical element, which is found in nature in the form of borax and kernite. While it has been used since old times, it has gained wide popularity and extensive usage by the advancement of technology. Boron compounds are now used all over the world in almost every industry from electronics to medical applications, from space technology to military and nuclear industries, etc. Turkey holds an approximately $70 \%$ share of boron deposits and takes the first 
place with a reserve of 1.8 million tons, followed by the United States and Argentina [7, 8].

The only producer of boron in Turkey is ETI Holding. It was reported that the annual production is 320,000 tons of borate pentahydrate and 60,000 tons of dominant boron pentahydrate salt $\left(\mathrm{Na}_{2} \mathrm{~B}_{4} \mathrm{O}_{7} \cdot 5 \mathrm{H}_{2} \mathrm{O}\right.$; tincal). Tincal and colemanite are commercially valued output products of boron. Tincal is used in borax pentahydrate, decahydrate, and sodium perborate production $[9,10]$. According to the State Planning Organization report [11], approximately 900,000 tons of boron derivative waste are generated annually. During the tincal production, two different types of waste in the form of the clay material are generated, with a total amount of 120,000 tons per year [12]. Due to the extensive range of uses in the industry, large amounts of boron derivative waste are generated, and as a result, large volumes of waste covering the large landfill areas are progressively increasing in terms of environmental scale. On the other side, there is the economic consideration that these types of waste are high-value products, and therefore, their reuse can be cost-effective.

There are considerable efforts and approaches by several researchers in multidisciplinary areas concerning the use of these wastes as by-products. Since there are oxides in the chemical composition of tincal concentrator waste (clay waste, $\mathrm{CW}$ ) (such as $\mathrm{SiO}_{2}, \mathrm{Al}_{2} \mathrm{O}_{3}, \mathrm{Fe}_{2} \mathrm{O}_{3}$, and $\mathrm{CaO}$ ) with puzzolonic characteristics, it has the potential to be used in construction technology. Topcu and Boga [13], Demir and Keles [14], and Kavas [15] carried out studies which used CW in cement, concrete, and mud brick. The results showed that the mechanical performance of these materials enhanced significantly due to the addition of CW. Sevim [16], Ozdemir and Ozturk [17], and Ozdemir and Uğurlu [18] also found that use of waste as additives in concrete can increase the compressive strength of the concrete up to $30 \%$. The CW was found to show an immediate, positive effect on the strength characteristics of treated concrete.

Despite these indicators, studies on the use of $\mathrm{CW}$ as a stabilizer in geotechnical literature are limited. Banar et al. [19] investigated the geotechnical and structural properties of CW as an impermeable liner in solid waste landfill sites. However, the effect of CW on the treated soils' strength characteristics has not been addressed.

Lack of experimental studies on CW-treated soils has motivated this study. In order to better understand the mechanical behavior of any material to be used as a stabilizer in geotechnical engineering, it is necessary to perform extensive studies with different types of soils.

The objective of this study is to determine the factors affecting the dynamic characteristics of $\mathrm{CW}$-treated/untreated cohesive soils. The cyclic response of each CW/soil mixture is presented and can be used as a general guideline.

\section{Resonant Column and Torsional Shear Testing System}

The crucial parameters in the design of geostructures resting on soils subjected to dynamic loadings, such as traffic or machinery vibrations, are maximum shear modulus $G_{\max }$, strain-dependent shear modulus ratio $G / G_{\max }$, and straindependent damping ratio $\mathrm{D}$. In the determination of these parameters in the laboratory, resonant column and dynamic torsional shear testing are widely used. In this study, a coupled device acting as a resonant column (RC) and the dynamic torsional shear apparatus (DTS) were used. ASTM D 4015 [20] and JGS 0543-2009 [21] describe details about the testing and data analysis. The main advantage is that it is designed to test the dynamic deformation characteristics of soil samples over a wide range of cyclic strain amplitudes $\left(\gamma \approx \% 10^{-4}\right.$ to $\left.\% 10^{-1}\right)$.

RC-DTS is a fixed-free system wherein the sample is fixed at the bottom cap and free to rotate at the top cap at its fundamental frequency via a drive system (Figure 1). Sinusoidal torsional excitation is applied to the top of the specimen by an electric motor. Torsional cyclic load with constant or variable amplitude can be applied over a range of frequencies to obtain the response curve. By measuring the motion from the top cap (free-end), the velocity of the propagating wave and the degree of material damping can also be determined. The shear modulus is calculated from the derived velocity and the density of the sample. During cyclic torsional shear testing, cyclic torsional stress amplitude is increased with each prescribed number of cycles to obtain the strain-dependent shear modulus and damping values.

\section{Materials Used}

The objective of the soil treatment is to alter the structure of unstable soils into improved and sound soils by increasing the stiffness and durability. It is stated that the plasticity index (PI) is the key parameter which controls the dynamic response of fine-grained soils $[22,23]$. Therefore, kaolinite and montmorillonite clays that cover the typical range of the plasticity index have been chosen as "parent materials." Kaolinite, having a plasticity index of $11 \%$, represents the lower end of the plasticity scale. Montmorillonite has a plasticity index of 93\%, representing the upper limit of the plasticity index scale.

Boron containing CW is the additive material. It was obtained from Eti Kirka Boron Works. To identify composition of the clay waste, X-ray diffraction (Philips PW 1830) analyses were performed. The data are presented in Table 1. The dominant phases in the XRD pattern are $\mathrm{CaMg}$ $\left(\mathrm{CO}_{3}\right)_{2}$ (dolomite), $\mathrm{MgO}$ (periclase), $\mathrm{Na}_{2}\left[\mathrm{~B}_{4} \mathrm{O}_{5}(\mathrm{OH})_{4}\right] \cdot 3 \mathrm{H}_{2} \mathrm{O}$ (tincalconite), $\mathrm{SiO}_{2}$ (quartz) $\left(\mathrm{Ca}_{6} \mathrm{Al}_{1.5} \mathrm{Si}_{0.5}\left(\mathrm{SO}_{4}\right)_{2} \mathrm{~B}\right.$ $(\mathrm{OH})_{12} \mathrm{O}_{4} \cdot 26\left(\mathrm{H}_{2} \mathrm{O}\right)$ (charlesite), and $\mathrm{CaCO}_{3}$ (calcite). The $\mathrm{CW}$ is a white-light gray-colored substance and contains low amounts of silica $\left(\mathrm{SiO}_{2}\right)$, alumina $\left(\mathrm{Al}_{2} \mathrm{O}_{3}\right)$, and iron oxide $\left(\mathrm{Fe}_{2} \mathrm{O}_{3}\right)$ which can be considered slightly pozzolanic.

Calcium-based stabilizers such as lime, ordinary Portland cement, and fly ash have been widely used for decades due to their pozzolanic properties in the treatment of unstable soils. For high pozzolanic reaction, ASTM C618-02 requires a total amount of $\mathrm{SiO}_{2}+\mathrm{Al}_{2} \mathrm{O}_{3}+\mathrm{Fe}_{2} \mathrm{O}_{3}$ higher than $70 \%$. However, as seen in Table 1, this amount in CW is almost $20 \%$.

3.1. Sample Preparation. The sample notation used Kln for kaolinite, Mnt for montmorillonite, and CW for clay waste. 


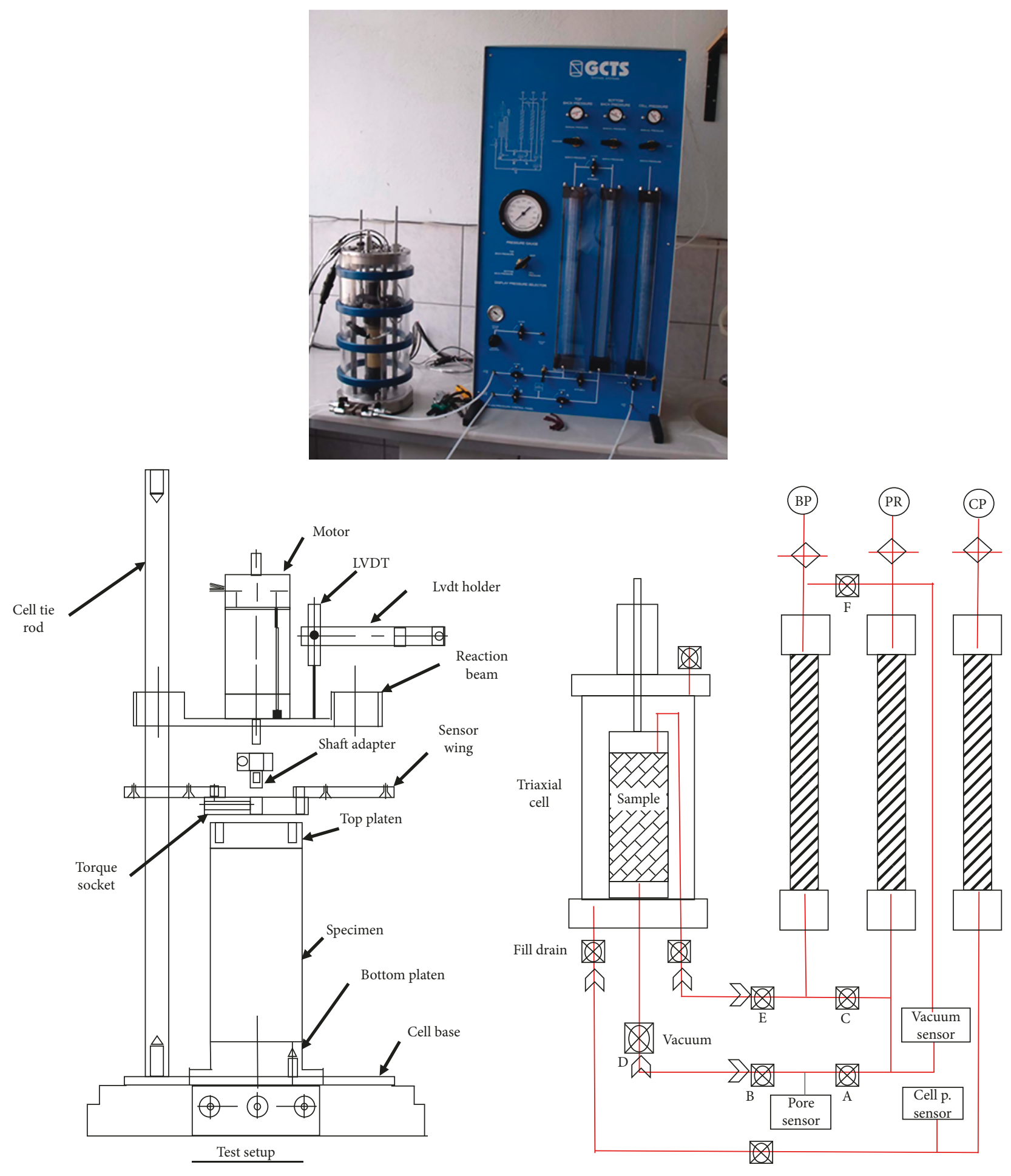

Figure 1: Resonant column/torsional shear system used in this study.

For example, untreated kaolinite clay (the control sample) represented by Kln $+0 \% \mathrm{CW}$ and kaolinite soil mixed with $2 \% \mathrm{CW}$ were represented by $\mathrm{Kln}+2 \% \mathrm{CW}$. The images of the samples used in the study are presented in Figure 2.

Before pulverization, the $\mathrm{CW}$ is air-dried for two months at room temperature and then oven-dried at $60^{\circ} \mathrm{C}$ for 24 hours. This kind of process is chosen because of the open storage conditions, and therefore, the CW contains some amount of moisture. After that, the $\mathrm{CW}$ is pulverized to powder and sieved through no. 100 mesh. The physical and geotechnical properties of the CW are presented in Table 1. The CW is also classified according to its physical particle characteristics and consists of $1.5 \%$ sand, $20.8 \%$ silt, and $77.6 \%$ clay. According to USCS, it is classified as fat clay $(\mathrm{CH})$. Physical characteristics of $\mathrm{CW}$ along with "parent materials" are shown in Table 2. 
TABle 1: Chemical components and physical characteristics of clay waste.

\begin{tabular}{lccc}
\hline Chemical component & Weight $(\%, \mathrm{w} / \mathrm{w})$ & \multicolumn{1}{c}{ Mechanical characteristics } \\
\hline $\mathrm{B}_{2} \mathrm{O}_{3}$ & 18.80 & Blaine $\left(\mathrm{cm}^{2} / \mathrm{g}\right)$ & 2820 \\
$\mathrm{CaO}$ & 14.90 & Initial setting time & $28 \mathrm{~h} 07 \mathrm{~min}$ \\
$\mathrm{SiO} 2$ & 16.03 & Final setting time & $102 \mathrm{~h} 15 \mathrm{~min}$ \\
$\mathrm{MgO}$ & 13.85 & Residue on $200 \mu \mathrm{m}(\%)$ & 0.9 \\
$\mathrm{Na}_{2} \mathrm{O}$ & 5.16 & Residue on $90 \mu \mathrm{m}(\%)$ & - \\
$\mathrm{Al}_{2} \mathrm{O}_{3}$ & 2.58 & - & - \\
$\mathrm{Fe}_{2} \mathrm{O}_{3}$ & 1.89 & - & - \\
$\mathrm{K}_{2} \mathrm{O}$ & 1.43 & - & - \\
Loss on ignition & 25.36 & \multicolumn{2}{c}{} \\
\hline
\end{tabular}

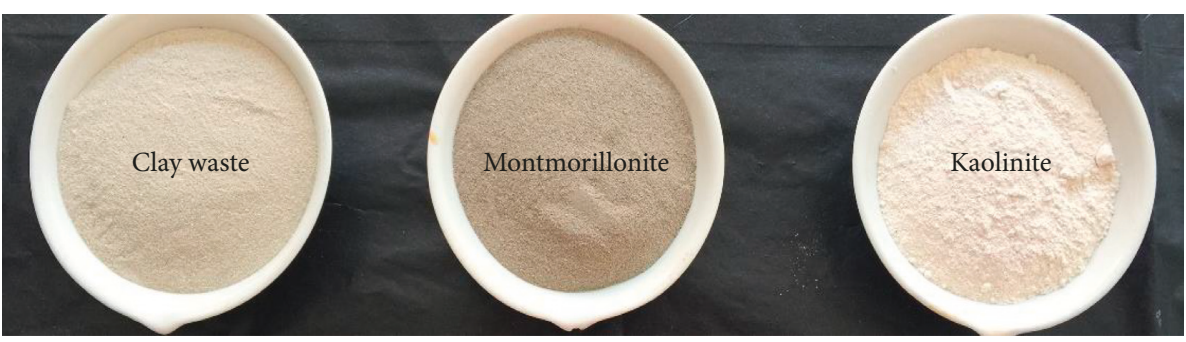

Figure 2: Materials used in the study.

TABLE 2: Physical characteristics of the materials.

\begin{tabular}{lcccr}
\hline Material & Kaolin & Montmorillonite & Clay waste & \multicolumn{1}{c}{ Standards } \\
\hline Particle size $(\mathrm{mm})$ & $<0.1$ & $<0.1$ & 58 & ASTM D7928-17 \\
Liquid limit (\%) & 36 & 140 & 28 & ASTM D4318-10 \\
Plastic limit (\%) & 25 & 47 & 30 & ASTM D4318-10 \\
Plasticity index (\%) & 11 & 93 & 2.78 & ASTM D4318-10 \\
Specific gravity & 2.69 & 2.63 & ASTM D854-10 \\
\hline
\end{tabular}

Untreated control samples were prepared with Kln and Mnt clay at optimum moisture contents. In practical applications, the amount of the stabilizer used in stabilization of fine-grained soils is generally less than $8-10 \%$. Therefore, pulverized CW was mixed with Kln and Mnt at 2, 4, 6, and $8 \%$ of the dry weight of the dry clay. To obtain a homogeneous mix, materials were mixed in a mechanical mixer for 15 minutes. Atterberg limits were performed for each mixture. It is observed that the liquid limit and plasticity increases as CW content increases (Table 3).

The standard proctor tests were performed to determine the compaction parameters. For Kln clay, compaction (ASTMD-698) [24] was performed right after the mixing process. However, Mnt soil was kept at room temperature for $2 \mathrm{hr}$ to allow for any possible volume changes before compaction, as suggested in [25]. Samples were prepared according to the compaction parameters. The compaction characteristics of the mixtures are given in Table 4. It can be seen that the increase of CW affected the compaction characteristics. In all samples, optimum moisture content has increased. The samples were trimmed to a diameter and height of $50 \mathrm{~mm}$ and $105 \mathrm{~mm}$, respectively. The trimmed samples were then wrapped with a plastic film and placed into a glass desiccator. Both treated and untreated control samples were subjected to 7 days of curing time.
TABLE 3: Notation used for the mixtures, mixture ratios, and related Atterberg limits.

\begin{tabular}{lcccccc}
\hline $\begin{array}{l}\text { Specimen } \\
\text { notation }\end{array}$ & $\begin{array}{c}\text { CW } \\
(\%)\end{array}$ & $\begin{array}{c}\text { Kln } \\
(\%)\end{array}$ & $\begin{array}{c}\text { Mnt } \\
(\%)\end{array}$ & $\begin{array}{c}\text { LL } \\
(\%)\end{array}$ & $\begin{array}{c}\text { PL } \\
(\%)\end{array}$ & $\begin{array}{c}\text { PI } \\
(\%)\end{array}$ \\
\hline Kln + 0\% CW & 0 & 100 & - & 36 & 25 & 11 \\
Kln + 2\% CW & 2 & 98 & - & 47 & 33 & 14 \\
Kln + 4\% CW & 4 & 96 & - & 47 & 39 & 8 \\
Kln + 6\% CW & 6 & 94 & - & 48 & 33 & 15 \\
Kln + 8\% CW & 8 & 92 & - & 49 & 31 & 18 \\
Mnt + 0\% CW & 0 & - & 100 & 140 & 47 & 93 \\
Mnt + 2\% CW & 2 & - & 98 & 99 & 33 & 66 \\
Mnt + 4\% CW & 4 & - & 96 & 83 & 30 & 53 \\
Mnt + 6\% CW & 6 & - & 94 & 78 & 40 & 38 \\
Mnt + 8\% CW & 8 & - & 92 & 73 & 37 & 36 \\
\hline
\end{tabular}

3.2. Testing Procedure. In various practical applications, such as subgrade layer performance, the soil is subjected to a state of stress between 50 and $100 \mathrm{kPa}$. Hence, samples were consolidated at a mean effective pressure of $50 \mathrm{kPa}$ for 24 hours. After the consolidation process, all samples were subjected to undrained cyclic loading. The tests were conducted on control and treated soils compacted to their maximum dry density at optimum moisture content. In each test, the cyclic stress was started from very low values to enable very low values of strain in order to determine the 
TABle 4: Summary of compaction tests.

\begin{tabular}{lcccc}
\hline \multirow{2}{*}{ CW content (\%) } & \multicolumn{2}{c}{ Kaolinite } & \multicolumn{2}{c}{ Montmorillonite } \\
& Optimum water content (\%) & Maximum dry density & Optimum water content (\%) & Maximum dry density \\
\hline 0 & 29.6 & 1.53 & 32.4 & 1.25 \\
2 & 39.5 & 1.37 & 36.7 & 1.15 \\
4 & 40.5 & 1.21 & 36.9 & 1.09 \\
6 & 40.9 & 1.22 & 37.2 & 1.07 \\
8 & 42.5 & 1.25 & 38.5 & 1.06 \\
\hline
\end{tabular}

maximum shear modulus, $G_{0}$, and minimum damping ratio, $D_{\text {min }}$. After that, cyclic stress amplitudes progressively increased step by step every five cycles, to high strain levels, to determine strain-dependent shear modulus and damping ratio (strain range of $10^{-3}-10^{1} \%$ ). The third cycle was selected from each five cycles as the representative cycle to evaluate the stress-strain characteristics. The shear modulus and damping properties were evaluated for each representative cycle. The loading pattern used in the study is presented in Figure 3.

\section{Results and Discussion}

The stress-strain curves of untreated and treated samples, in the form of the degraded hysteresis type, are presented in Figures 4 and 5, respectively. The vertical axis plots cyclic stress ratio, and the horizontal axis plots cyclic strain. The curves presented in Figures 4(a) and 4(b) are for untreated Kln and Mnt samples under an effective consolidation pressure of $50 \mathrm{kPa}$. Figures 5(a) and 5(b) shows the same samples in the same test conditions but treated with $2 \% \mathrm{CW}$. For untreated Kln and Mnt samples, the area of the hysteresis loops increased as the cyclic strain amplitude increased. It is to be noted that the stress-strain path of the Kln sample is different from the Mnt sample, which can be attributed to the difference on plasticity. However, the hysteresis curves of both samples are symmetrical along the $x-y$ axis. The behavior of the treated samples is somewhat different, as seen in Figure 5. The hysteresis curves change shape from concave to convex. As the test progresses, the loops became asymmetrical along the $x-y$ axis, showing that the energy dissipation differs during loading and unloading conditions. This fact can be attributed to two factors. The first one is uniformity of the sample. Even though the sample preparation method is consistent with the amount of energy applied to the mixture, the sample may not be uniform. The second factor is the puzzolonic reaction of CW. The effect of the CW amount is discussed in the following paragraphs.

In the assessment of dynamic properties of soils, generally two characteristic curves have the most importance. These are strain-dependent shear modulus curves, that is, degradation of rigidity with shear strain and straindependent damping ratio curves, that is, variation of energy dissipation versus the shear strain. Due to the nonlinear behavior of soils, shear modulus and damping ratio vary with the cyclic strain amplitude. Therefore, the same behavior can be expected with CW-treated samples.

Figure 6 presents the strain-dependent stress-strain curves of untreated control samples. The initial shear

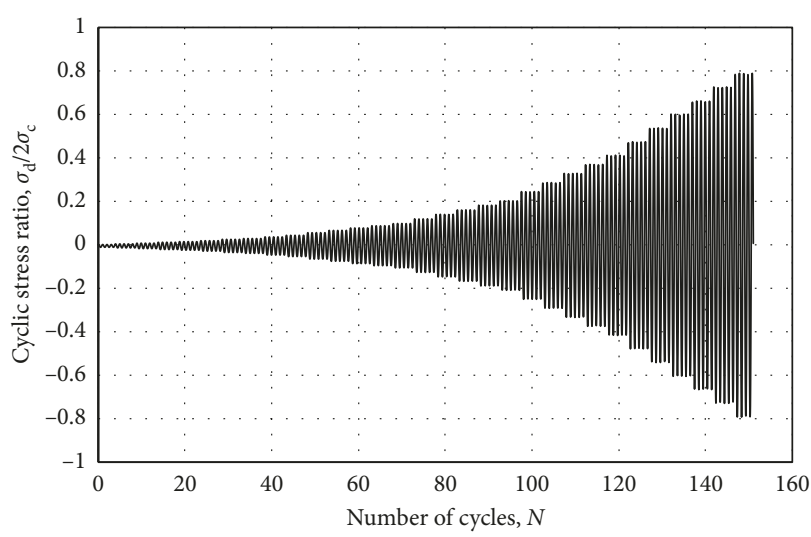

Figure 3: Typical cyclic loading pattern used in the study.

modulus and minimum damping ratio values were determined by using the resonant column test. Straindependent variation of shear modulus and damping ratio were determined by conducting a cyclic torsional shear test. As indicated in Figure 6(a), the shear modulus decreases with increasing cyclic strain amplitude. The reduction begins at a strain level of $3 \times 10^{-3} \%$ and $6 \times 10^{-1} \%$ for Kln and Mnt clay, respectively. This strain level is considered as a threshold between nonlinear elastic and elastoplastic response of cohesive soils [26]. It is also observed from Figure 6(b) that the initial shear modulus of Mnt clay is smaller than that of the Kln clay. As the Mnt clay has greater optimum water content and smaller maximum dry density with respect to Kln clay, it is obvious that it will have smaller shear modulus values than those obtained from Kln. Figure 6(c) shows the damping behavior of the same samples. The damping ratio of Kln is greater than the Mnt clay for all strain levels and getting greater as the strain level increases. Mnt clay shows a constant damping behavior almost up to a strain of $10^{-2} \%$.

The strain-dependent shear modulus and damping ratio of CW-treated Kln and Mnt samples are shown in Figures 7 and 8 , respectively. These curves are good representations by which the effect of $\mathrm{CW}$ on each soil is understood. The maximum shear modulus of untreated Kln was $79 \mathrm{MPa}$, whereas the maximum shear modulus of treated samples ranged between 76 and $97 \mathrm{MPa}$ (Figure 7(a)). The maximum shear modulus of untreated Mnt is $11 \mathrm{MPa}$, whereas the maximum shear modulus of $\mathrm{CW}$-treated Mnt ranged from 15 to $38 \mathrm{MPa}$.

Compared to the control specimen for each mixture of $\mathrm{Mnt}$, the influence of $\mathrm{CW}$ on the stiffness is quite significant 


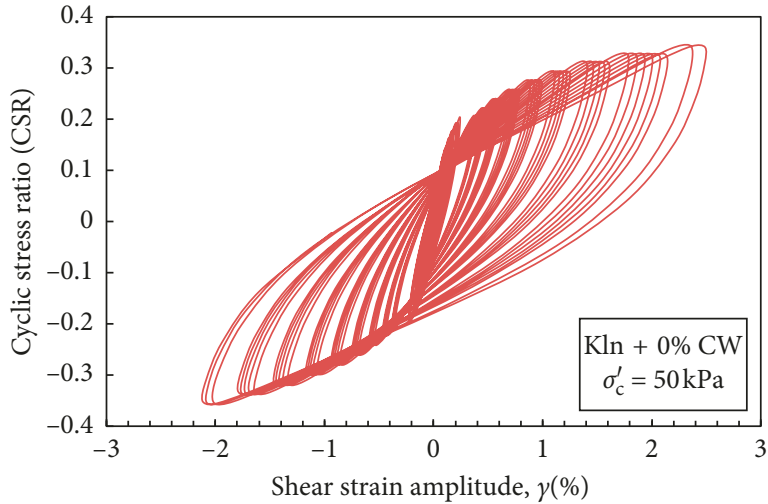

(a)

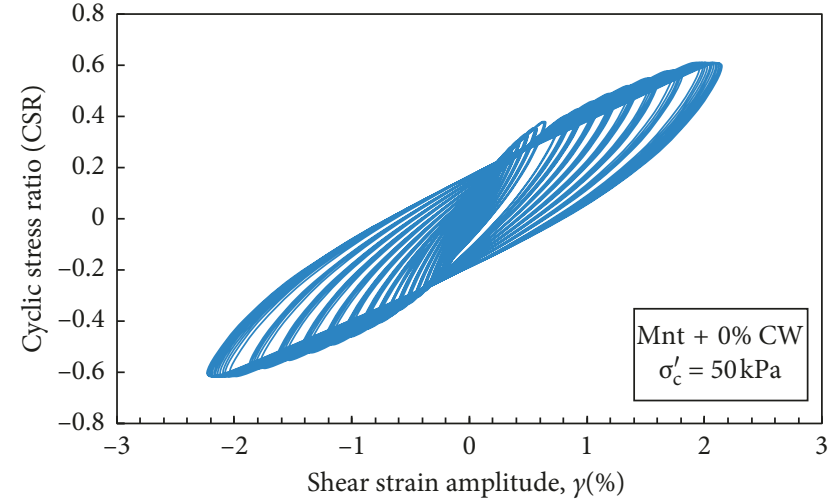

(b)

Figure 4: Hysteresis loops of control samples: (a) Kln $+0 \% \mathrm{CW}$; (b) Mnt $+0 \% \mathrm{CW}$.

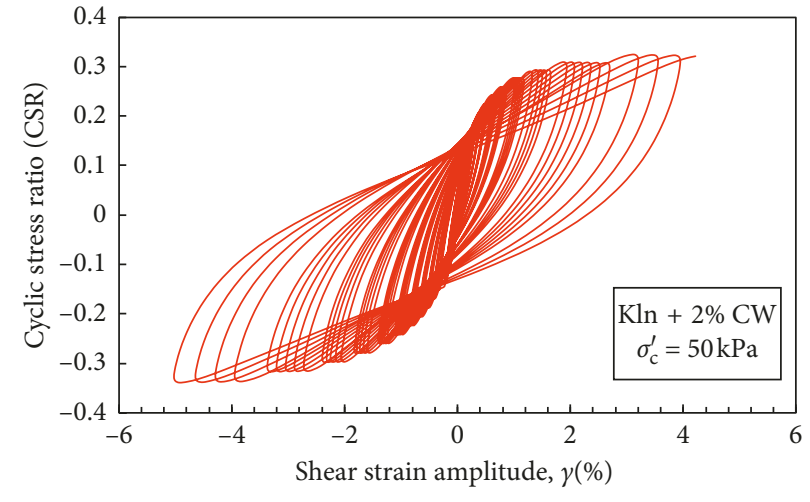

(a)

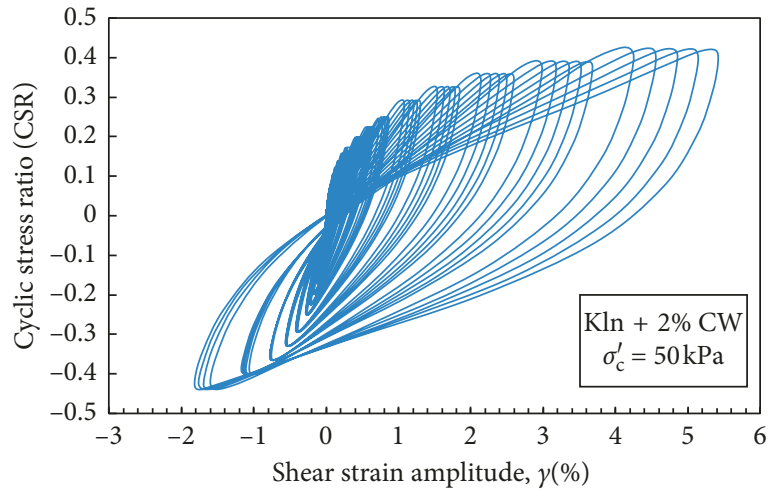

(b)

Figure 5: Hysteresis loops of samples with $2 \% \mathrm{CW}$ added: (a) $\mathrm{Kln}+2 \% \mathrm{CW}$; (b) $\mathrm{Mnt}+2 \% \mathrm{CW}$.
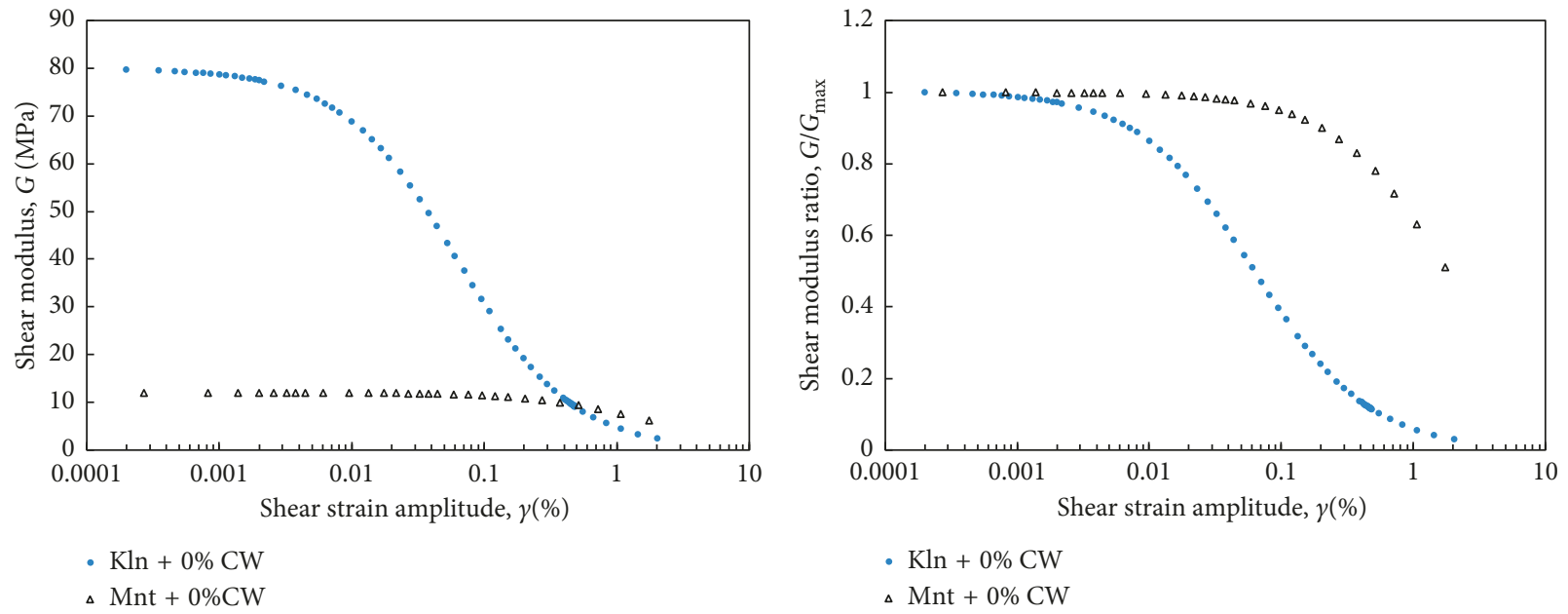

(a)

FIgUre 6: Continued. 


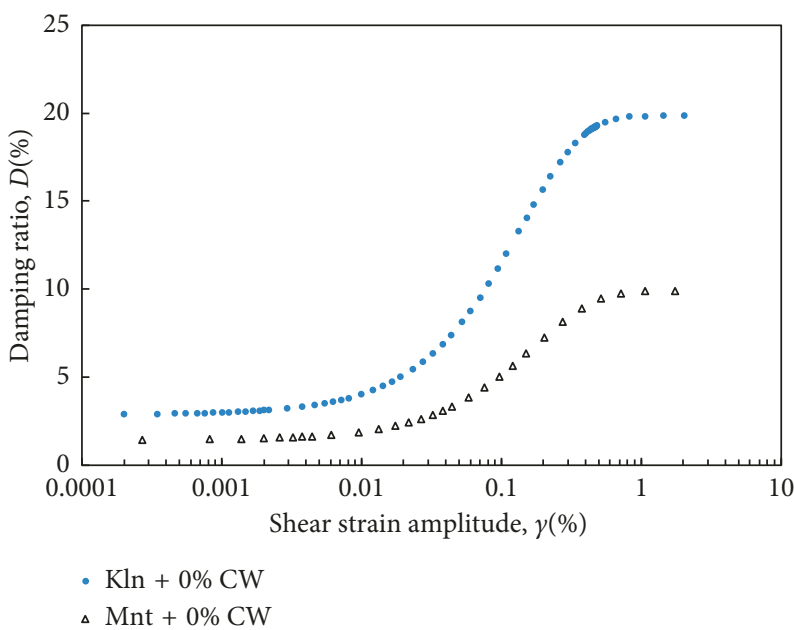

(c)

FIgURE 6: Comparison of (a) initial shear modulus, (b) shear modulus ratio, and (c) damping ratio of control samples.

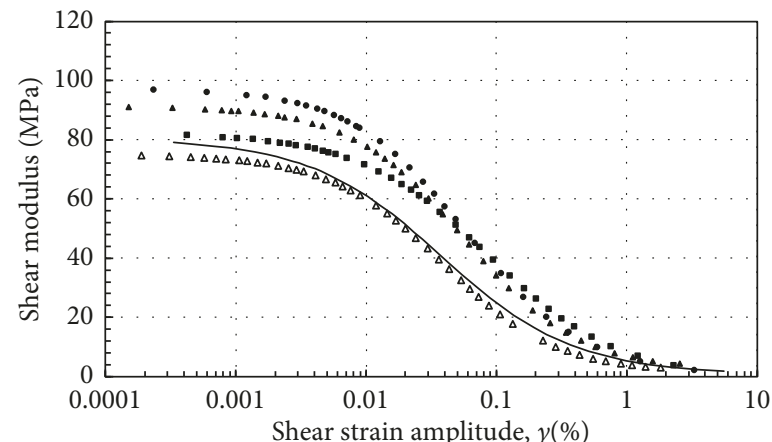

$\begin{array}{lll}\mathrm{K} \ln +0 \% \mathrm{CW} & -\mathrm{Kln}+6 \% \mathrm{CW} \\ \text {. } \mathrm{Kln}+2 \% \mathrm{CW} & \triangle & \mathrm{Kln}+8 \% \mathrm{CW} \\ \text {. } \mathrm{Kln}+4 \% \mathrm{CW} & & \end{array}$

(a)

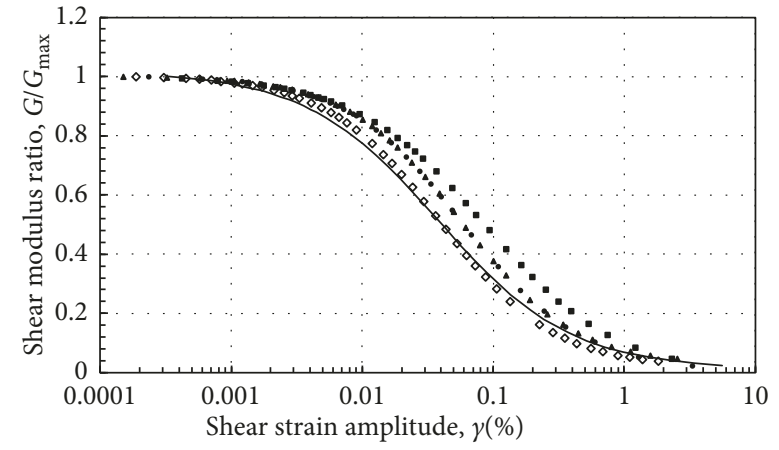

- $\mathrm{Kln}+0 \% \mathrm{CW}$

- $\mathrm{Kln}+6 \% \mathrm{CW}$

ه $\mathrm{Kln}+8 \% \mathrm{CW}$

(b)

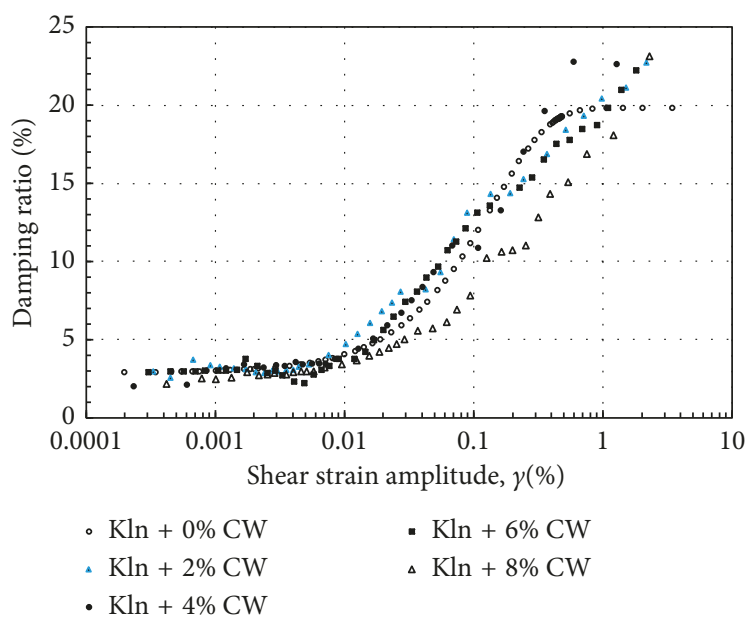

(c)

Figure 7: Comparison of (a) initial shear modulus, (b) shear modulus ratio, and (c) damping ratio of Kln + CW samples. 


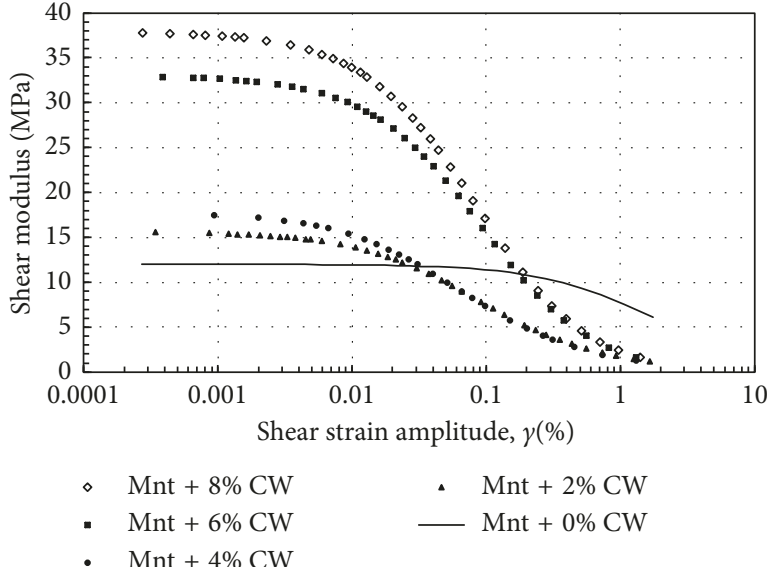

(a)

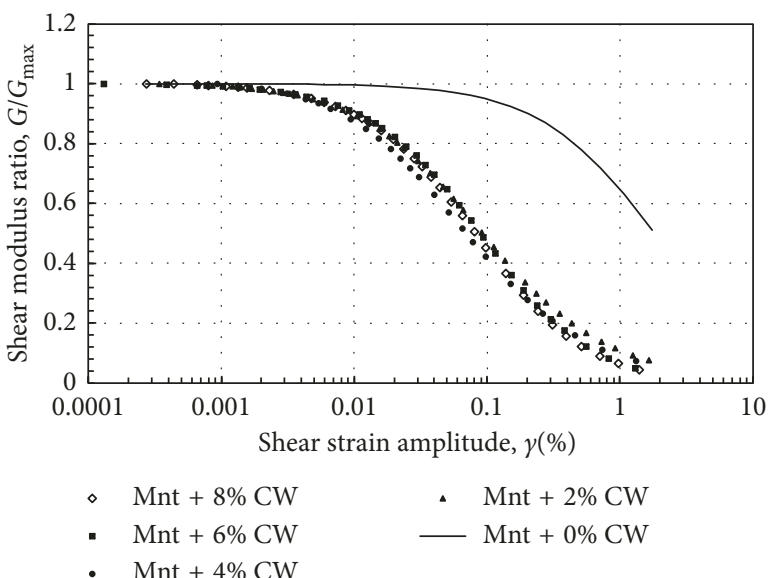

(b)

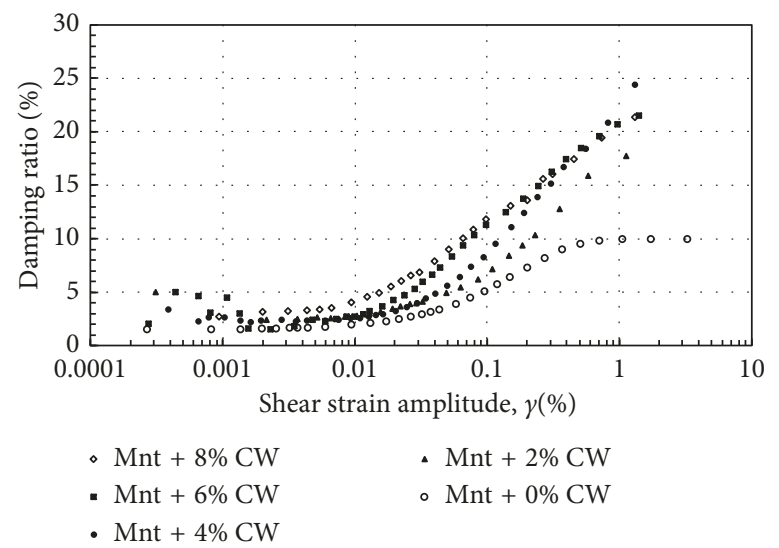

(c)

FIGURE 8: Comparison of (a) initial shear modulus, (b) shear modulus ratio, and (c) damping ratio of Mnt $+\mathrm{CW}$ samples.

and predominant compared to Kln. As indicated in Figure $8(\mathrm{a})$, when $2 \% \mathrm{CW}$ is added to Mnt, the initial shear modulus increased about $50 \%$ and gradually increased with the increase of $\mathrm{CW}$, whereas adding $2 \% \mathrm{CW}$ to $\mathrm{Kln}$ increased the initial shear modulus by just $10 \%$ (Figure $7(\mathrm{a})$ ). Such an increase in rigidity can be attributed to the pozzolanic activity of CW. That amount of CW increased the rigidity of the sample; however, adding more that $4 \%$ (in this case $6 \%$ and $8 \%$ ) amount of clay waste showed that it does not have an positive effect on the strain-dependent shear modulus of the mixture. Montmorillonite clay has the most dramatic swelling capacity; therefore, the reaction with the clay waste was somewhat different from kaolinite clay in terms of their rigidity under cyclic loading. The dynamic behavior of montmorillonite is affected by higher contents of clay waste compared to kaolinite.

The more rigid the sample, the smaller the strain at which degradation takes place (Figures $7(\mathrm{~b})$ and $8(\mathrm{~b})$ ). In addition, as can be seen from Figures 5(a) and 6(a), when the strain level increases to $0.1 \%$ the shear modulus values of all treated samples reduced about to $50-60 \%$ of their initial value. In Figure $7(\mathrm{a}), \mathrm{Kln}+0 \% \mathrm{CW}$ and $\mathrm{Kln}+8 \% \mathrm{CW}$ curves were almost identical, indicating that it is the limiting amount for stabilization of Kln. Kln $+6 \% \mathrm{CW}$ curve is placed far above to the Kln $+8 \% \mathrm{CW}$ curve and closer to the Kln
$+2 \% \mathrm{CW}$ and $\mathrm{Kln}+4 \% \mathrm{CW}$ curves. The degradation curves are almost the same for Mnt samples treated with CW. For both clays and CW contents, the gain in stiffness had been gradually lost when the shear strain amplitude approached a value of $2-3 \%$, which is the failure (plastic) state. The approximate ranges of the shear strain producing more elastoplastic and plastic strain range for treated soils are much below the untreated control sample. Up to the $0.02 \%$ strain, the control sample exhibits elastic behavior. However, the treated soils exhibit elastic behavior up to $0.002 \%$ strain. The rigidity of montmorillonite increases with the treatment; however, its elastic range decreases.

The damping curves presented in Figures 7(c) and 8(c) show similar behavior to those obtained in shear modulus curves. The addition of $\mathrm{CW}$ results in a reduction in damping, but the effect is not in the same fashion as in shear modulus. Nevertheless, the rigidity due to the addition of $\mathrm{CW}$ results in a decrease in damping. The nature of the damping of soils is hysteretic. Most of the energy loss is due to the internal friction of soils. The damping ratio keeps almost constant for smaller cyclic strain amplitudes, regardless of treatment. It can be seen from Figure $7(\mathrm{c})$ that the $\mathrm{Kln}+8 \% \mathrm{CW}$ curve is located at the base of the graph, whereas $\mathrm{Kln}+2 \% \mathrm{CW}, \mathrm{Kln}+4 \% \mathrm{CW}$, and $\mathrm{Kln}+6 \% \mathrm{CW}$ curves are located above the control sample. CW-treated 


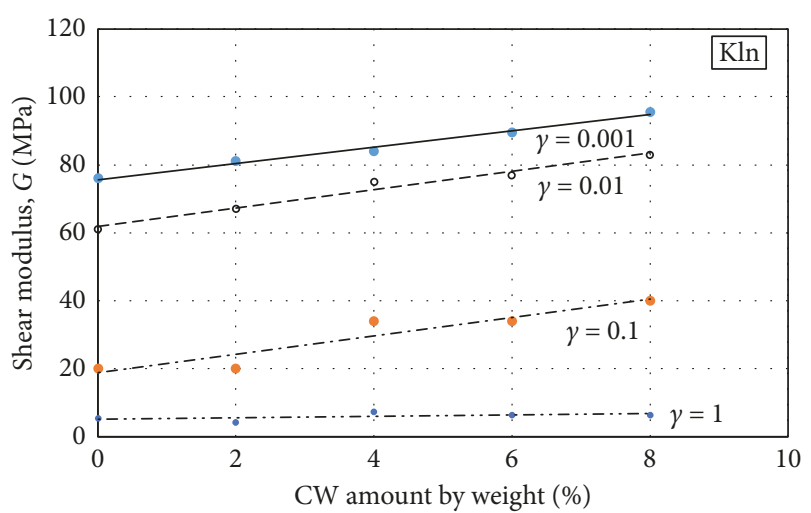

(a)

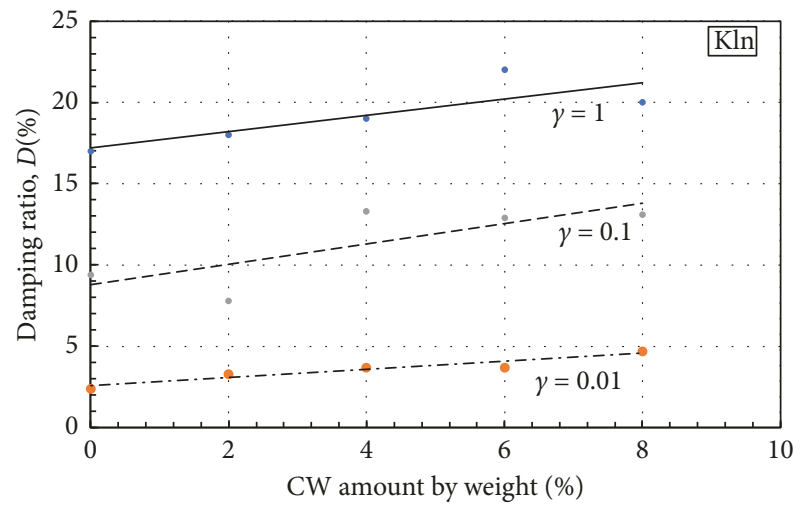

(c)

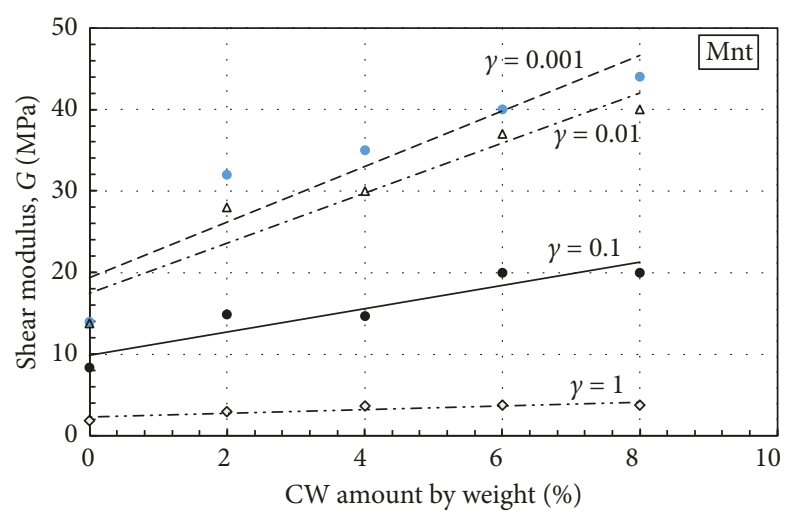

(b)

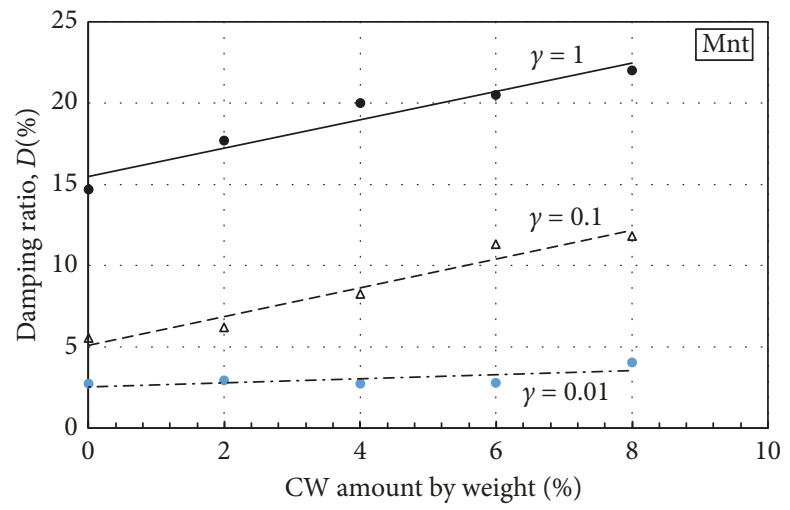

(d)

Figure 9: Change in shear modulus (a) and damping ratio (b) at different strain levels with respect to CW amount.

Mnt samples show practically the same behavior as that of $\mathrm{Kln}$; however, the effect of $\mathrm{CW}$ is more pronounced in Figure 8(a). For all treated Kln samples, damping ratio increases with increasing shear strain and reaches a constant value (Figure $7(\mathrm{c})$ ). The higher the rigidity, the lower the damping. With the addition of $\mathrm{CW}$, the damping ratio slightly increases for the same strain amplitude for Mnt clay (Figure 8(c)). The increase rate is not as substantial as the increase in shear modulus, yet as the strain amplitude increases, the damping ratio increases and converges to a certain value. As discussed in [25], the pozzolanic reaction between stabilizer and soil makes it difficult for the grains to reposition themselves, which causes less damping.

The effect of treatment can also be defined with different strain levels. As presented in Figure 9(a), the increase rate of shear modulus is much bigger in Mnt clay compared to Kln. This effect is lost as the samples approach to the plastic state at a strain of $1 \%$. This fact can also be demonstrated with damping ratio as seen in Figure 9(b). Even though damping behavior is not clear as those in shear modulus, samples are highly susceptible to CW treatment.

\section{Conclusions}

In all soil treatment designs, the aim is to improve the engineering characteristics of weak soil along with fundamental analysis and design techniques. In this study, the cyclic behavior of two clays mixed with a boron derivative waste was studied based on a set of resonant column and cyclic torsional shear tests. Initial shear modulus, minimum damping ratio, the strain dependency of shear modulus, and the damping of kaolin and montmorillonite clays mixed with the clay waste at different ratios were evaluated.

Test results showed that the treatment with $\mathrm{CW}$ provided more rigid samples compared with the untreated control samples, resulting higher $G$ values. For both clays, shear modulus decreases and damping ratio increases with increasing cyclic strain, which is a typical behavior of soils under cyclic loadings.

Shear modulus increases with added CW up to a strain amplitude of $0.01 \%$ for both clays. After passing through this strain threshold, there is no difference in the shear modulus of treated and untreated samples. The increase in the shear modulus can be explained by the cementation effect of CW. The treated clays, especially montmorillonite, behaved almost three times more rigidly in terms of initial shear modulus. The effect of CW on kaolinite is small compared to montmorillonite. The strong hydrogen bonds between Kln mineral sheets make the mineral stable and having a low cation exchange capacity makes its plasticity low. Mnt minerals contain much smaller sheets, much higher charge deficiency, and higher plasticity compared to Kln. 


\section{Data Availability}

The data used to support the findings of this study are included within the article as tables or graphs.

\section{Conflicts of Interest}

The authors declare that there are no conflicts of interest.

\section{Acknowledgments}

The authors would like to acknowledge the Eskisehir Osmangazi University, Scientific Research Project Unit, for the support of this work through Project No. 2018-1918.

\section{References}

[1] E. B. Pancar and M. V. Akpinar, "Comparison of effects of using geosynthetics and lime stabilization to increase bearing capacity of unpaved road subgrade," Advances in Materials Science and Engineering, vol. 2016, Article ID 7129356, 8 pages, 2016.

[2] N. Latifi, A. Rashid, S. Siddiqua, and S. Horpibulsuk, "Microstructural analysis of strength development in low and high swelling clays stabilized with magnesium chloride solution-a Green soil stabilizer," Applied Clay Science, vol. 118, pp. 195-206, 2015.

[3] B. D. Nath, K. A. Molla, and G. Sarkar, "Study on strength behavior of organic soil stabilized with fly ash," International Scholarly Research Notices, vol. 2017, pp. 1-6, 2017.

[4] R. Saadeldin and S. Siddiqua, "Geotechnical characterization of a clay-cement mix," Bulletin of Engineering Geology and the Environment, vol. 72, no. 3-4, pp. 601-608, 2013.

[5] S. Sánches-Moral, S. Sergio, J. Garcia-guinea, and A. Aparicio, "Lime pozzolana mortars in Roman catacombs: composition, structures and restoration," Cement and Concrete Research, vol. 35, no. 8, pp. 1555-1565, 2005.

[6] Q. Li, J. Chen, Q. Shi, and S. Zhao, "Macroscopic and microscopic mechanisms of cement-stabilized soft clay mixed with seawater by adding ultrafine silica fume," Advances in Materials Science and Engineering, vol. 2014, Article ID 810652, 12 pages, 2014.

[7] R. Kistler and C. Helvaci, "Boron and borates," in Industrial Minerals and Rocks, Society of Mining, Metallurgy and Exploration, Englewood, CO, USA, 6th edition, 1994.

[8] C. Helvaci and R. N. Alonso, "Borate deposits of Turkey and Argentina, a summary and geological comparison," Turkish Journal of Earth Sciences, vol. 9, pp. 1-27, 2014.

[9] O. Yilmaz, "Calsine tincal production from excavated material," Journal of the Faculty of Engineering and Architecture of Gazi University, vol. 29, no. 2, pp. 401-406, 2014.

[10] O. Sahin, N. Genli, and M. Ozdemir, "A new method for producing Anhydrous Puffed Borax," Chemical Engineering and Processing: Process Intensification, vol. 44, no. 1, pp. 1-6, 2005.

[11] The State Planning Organization, Boron, Soda Ash, and Chrome Chemicals, DPT Report No: 2776, SPO, Ankara, Turkey, 2008.

[12] U. Yenial and G. Bulut, "Utilization of mineral wastes for wastewater treatment," in Proceedings of Conference on Balkan Mineral Processing Conference, pp. 229-235, Belgrade, Serbia, June 2015.
[13] I. B. Topcu and A. R. Boga, "Effect of boron waste on the properties of mortar and concrete," Waste Management and Research, vol. 28, pp. 626-633, 2009.

[14] D. Demir and G. Keleş, "Radiation transmission of concrete including boron waste for 59.54 and $80.99 \mathrm{keV}$ gamma rays," Nuclear Instruments and Methods in Physics Research Section B: Beam Interactions with Materials and Atoms, vol. 245, no. 2, pp. 501-504, 2006.

[15] T. Kavas, "Use of boron waste as a fluxing agent in production of red mud brick," Building and Environment, vol. 41, no. 12, pp. 1779-1883, 2005.

[16] U. K. Sevim, "Colemanite ore waste concrete with low shrinkage and high split tensile strength," Materials and Structures, vol. 44, no. 1, pp. 187-193, 2011.

[17] M. Ozdemir and N. U. Ozturk, "Utilization of clay wastes containing boron as cement additives," Cement and Concrete Research, vol. 33, no. 10, pp. 1659-1661, 2003.

[18] M. Ozdemir and A. Uğurlu, "Evaluation of boron containing clay wastes in cement production," Materials and Manufacturing Processes, vol. 26, no. 9, pp. 1130-1135, 2011.

[19] M. Banar, Y. Guney, A. Ozkan, Z. Gunkaya, E. Bayrakci, and D. Ulutas, "Utilization of waste clay from boron production in bituminous geosynthetic barrier (GBR-B) production as landfill liner," International Journal of Polymer Science, vol. 2016, Article ID 1648920, 8 pages, 2016.

[20] ASTM D4015-87, Standard Test Methods for Modulus and Damping of Soils by Resonant-Column Method, 2002.

[21] JGS 0543-2009, Method for Cyclic Torsional Shear Test on Hollow Cylindrical Specimens to Determine Deformation Properties of Soils, 2009.

[22] T. Kokusho, Y. Yoshida, and Y. Esashi, "Dynamic properties of soft clay for wide strain range," Soils and Foundations, vol. 22, no. 4, pp. 1-18, 1982.

[23] M. Vucetic and R. Dobry, "Effect of soil plasticity on cyclic response," Journal of Geotechnical Engineering, vol. 117, no. 1, pp. 89-107, 1991.

[24] ASTM D698-Standard Test Methods for Laboratory Compaction Characteristics of Soil Using Standard Effort (600 kN$\left.\mathrm{m} / \mathrm{m}^{3}\right)$.

[25] K. Fahoum, M. S. Aggour, and F. Amini, "Dynamic properties of cohesive soils treated with lime," Journal of Geotechnical Engineering, vol. 122, no. 5, pp. 382-389, 1996.

[26] V. Okur and A. Ansal, "Stiffness degradation of fine-grained soils," Soil Dynamics and Earthquake Engineering, vol. 27, no. 9, pp. 843-854, 2007. 


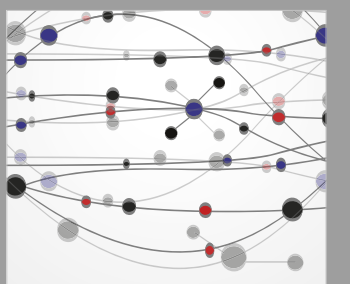

The Scientific World Journal
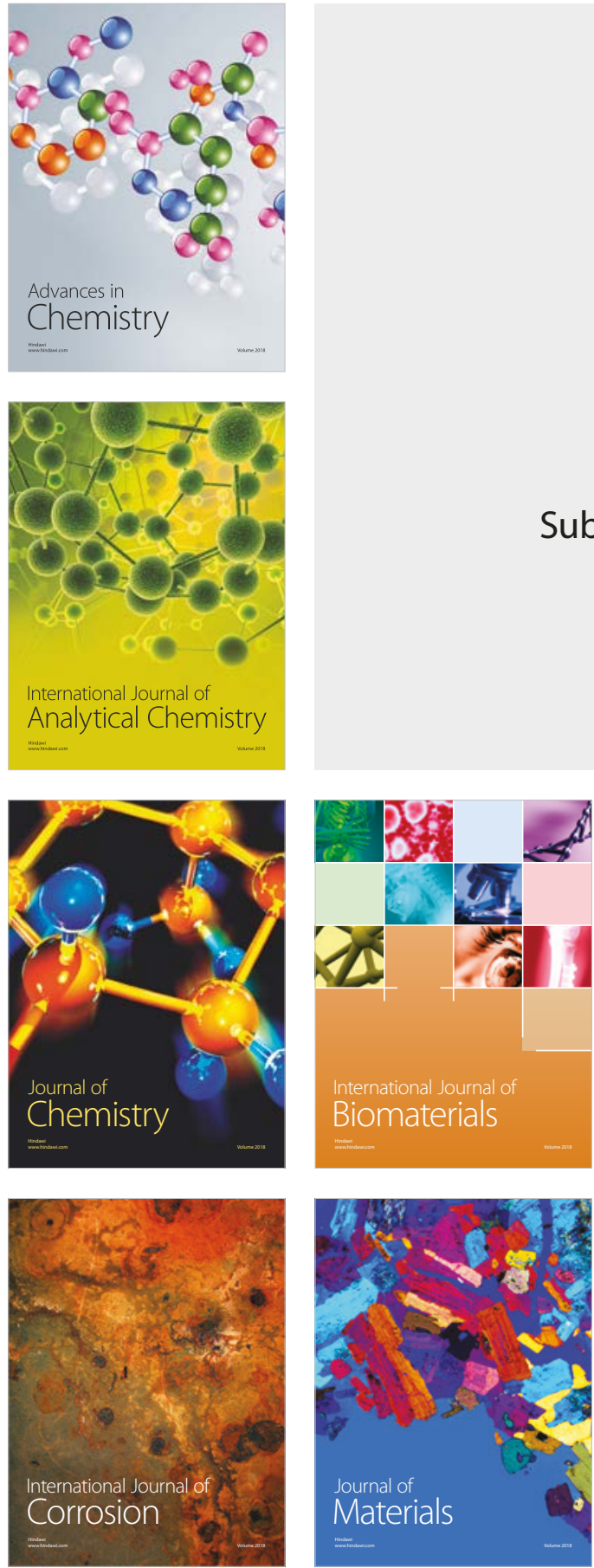

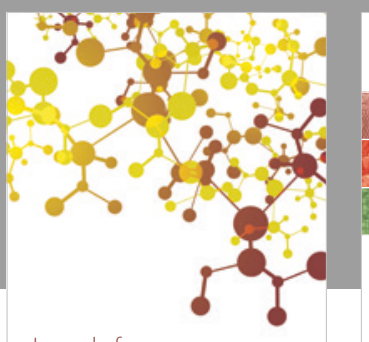

Journal of

Applied Chemistry
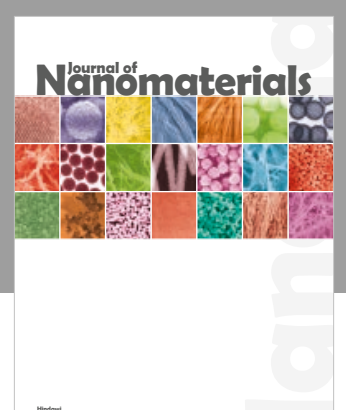

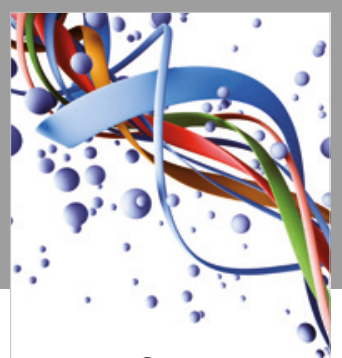

Scientifica

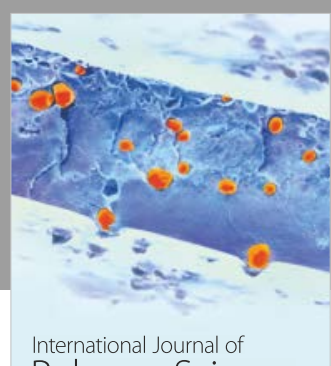

Polymer Science

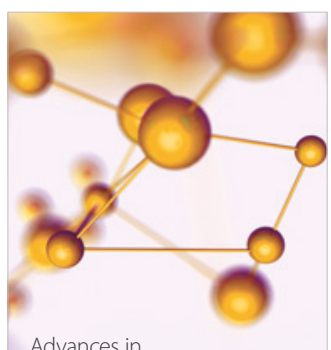

Physical Chemistry
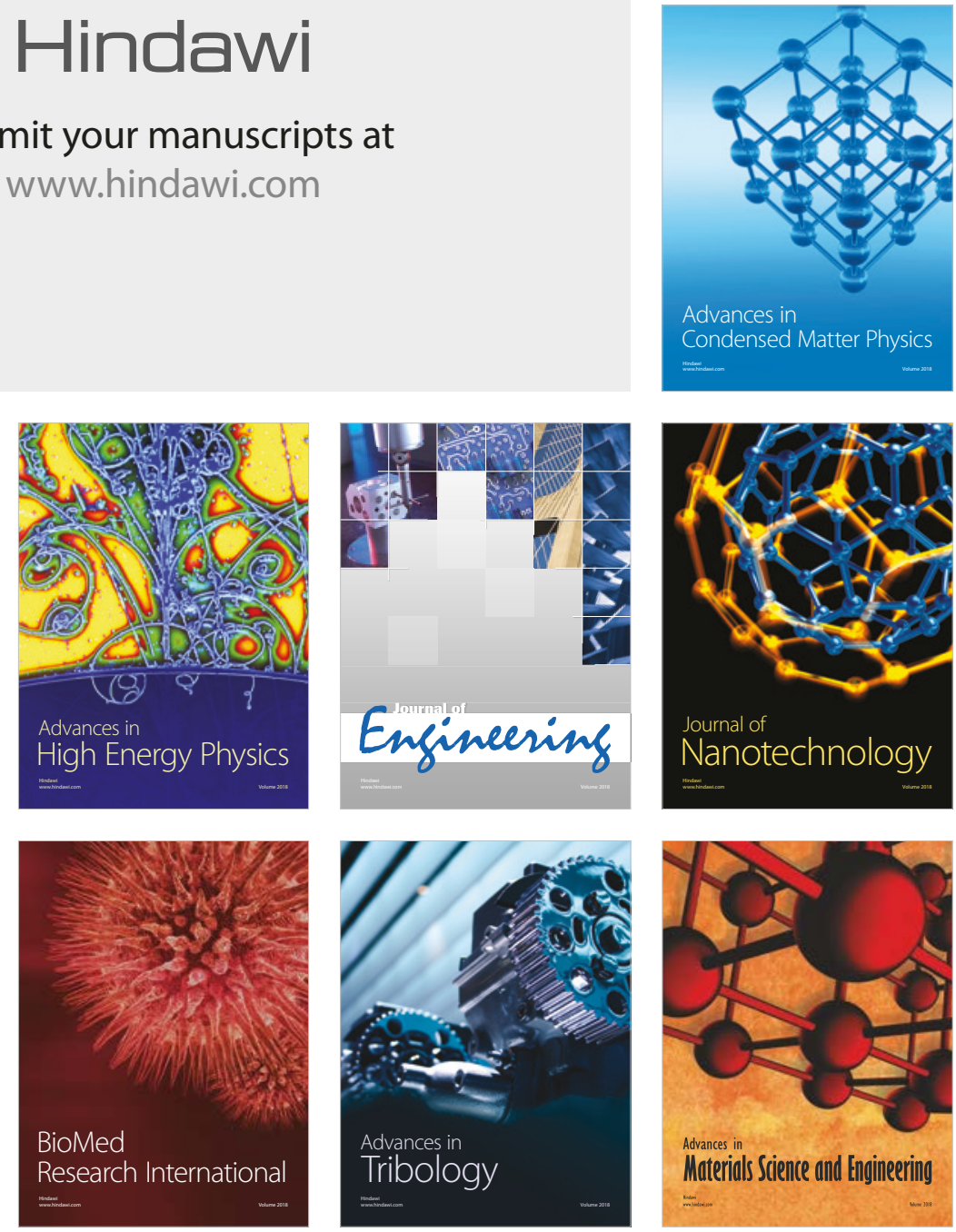